\title{
Indexation of dynamic and static geomechanical properties of a cemented aggregate for transportation engineering
}

\author{
António Viana da Fonseca, Miguel Ferreira Amaral, Fabrizio Panico*, Sara Rios \\ Dep. of Civil Engineering (FEUP), University of Porto, Portugal
}

\section{A R T I C L E I N F O}

\section{Article history:}

Available online 8 February 2014

\section{Keywords:}

Aggregate-cement

Geomechanical properties

Triaxial tests

Seismic waves

Indirect tensile tests

\begin{abstract}
A B S T R A C T
This paper presents an extensive experimental program aiming to the mechanical characterisation of an aggregate stabilised with cement. This geomaterial is the product of a quarry of limestone located in north region of Portugal. The aggregate is often used in current subgrading of infrastructures for transportation, namely in railway lines. Complementary, aggregate-cement admixtures are used for transition zones, such as in between deformable embankments on soft grounds lining on rigid structures, such as bridges founded on deep foundations, such as piles or similar. The demand for smooth transition between diverse stiffness zones implies an optimization of the composition of the enriched materials that will be used for such purpose, such as aggregate-cement admixtures. The optimization requires a thorough mechanical characterisation including dynamic tests, with recourse to geophysical techniques, cyclic and monotonic triaxial tests and, ideally, indexed to simple uniaxial compression and indirect tensile tests. The results that will be presented herein have allowed a good mechanical characterisation of the referred aggregate, in terms of the estimation of combinations of the cement content and the admixture compaction level, resulting in new correlations for design purposes.
\end{abstract}

(c) 2014 Elsevier Ltd. All rights reserved.

\section{Introduction}

Cementation is one basic intrinsic bias of most naturally occurring soil deposits and one that clearly separates their behaviour from that of artificially reconstituted soils (Leroueil and Vaughan, 1990). Both in natural state, or by the consequence of joining binders to remoulded soils that will be compacted by conventional procedures, the increase in structural bonding in soils turn them ideal for most purposes in geotechnical engineering problems (Mitchell, 1976). These artificial compacted cemented soils include soil-cement or lime-cement admixtures which

\footnotetext{
* Corresponding author.

E-mail addresses: viana@fe.up.pt (A. Viana da Fonseca), mfamaral@ fe.up.pt (M.F. Amaral), fabrizio.panico@fe.up.pt (F. Panico), sara.rios@ fe.up.pt (S. Rios).
}

have been used as very convenient materials for transportation infrastructures, such as subgrading in roads or railways (Viana da Fonseca et al., 2013). The dual benefit of cementation and non-saturation in some of these materials applications is especially relevant to the increase in stiffness and stability that has been obtained, for instance, in large and deep excavations in urban areas with a minimum impact in the surrounding infrastructures (Topa Gomes, 2009; Amaral et al., 2010).

Reliable experimental data about the behaviour of cemented soils is not vast in the literature for several reasons. The cementation of natural soils, such as residual soils (Vaughan and Kwan, 1984; Viana da Fonseca, 2003; Vinda da Fonseca and Coutinho, 2008) is both highly variable and frequently quite fragile, especially in open voids structured soils, like saprolitic soils, in one side, or aged granular natural soils, on the other side; hence it is difficult to obtain high quality undisturbed samples of naturally 
cemented soils. Moreover, in most cases destructive mechanical tests to assess the degree of effective bonding in a given sample have been conducted due to the difficulty of looking at the properties with non-destructive tests (e.g. Gasparre and Coop, 2008), thus increasing the number of specimens necessary to characterise them. Because of these problems, artificially cemented soils became an alternative for experimental studies of bonding effects in soils (e.g. Âhnberg, 2007; Rios et al., 2009), since controlled production allows for good repeatability and thus various compositional factors (binder type, binder content, compaction level or porosity) can be easily studied.

This paper aims to provide a study of a cemented limestone aggregate, usually adapted to transition zones providing a smooth or gradual evolution of strength and, mostly, of stiffness between two consecutive foundation systems of a platform, when referring to transportation infrastructures. In the transition zones, the traffic load tends to develop relative displacements in the less stiff subgrading foundations, increasing the deterioration of the track in those areas and increasing the risk of collapse and maintenance costs. The evolution of the permanent settlement is a function of soil's characteristics, conditioned by traffic loads intensity, in values, frequencies and lasting periods.

The stress state of subgrades under the pavements or railway tracks induced by these loadings have been studied by several authors [e.g., Heisey et al. (1982), Selig and Li (1994), Tatsuoka et al. (2002), Fortunato (2005), Lohani and Tatsuoka (2006), Werkmeister (2003), Viana da Fonseca et al. (2009a, 2013)] who have formulated distinct approaches. In the beginning of the 80 's, the computing capacity promoted the generalization of numeric simulation to recreate the behaviour of these structures. Finite elements method allows establishing elastoplastic and viscoelastic laws considering the elastic modulus degradation and frictional-cohesive strength (Fortunato, 2008).

These studies and the traffic speed/weight growing tendencies, revealed the importance of the application of stabilised geomaterials for railway pavements, especially, in the referred transition zones. Aware of this applicability and the need of having them characterised, this paper presents a framework which allows for the evaluation of some of the key geomechanical design parameters of a specific limestone aggregate-cement, using fundament correlations which take into account distinct testing approaches.

In what follows the materials, equipment and testing procedures employed in the experimental campaign are described. The results of that campaign are described and discussed, involving the dynamic stiffness properties characterisation by measuring small energy seismic wave's velocities with ultrasonic transducers (Khan et al., 2011), the tensile strength for diametrical compression test (Ghosh and Subbarao, 2006), and small to medium strain stiffness, together with strength properties, from triaxial tests with high precision local instrumentation (Tatsuoka and Kim, 1984; Symes and Burland, 1984; Viana da Fonseca, 1996; Cuccovillo and Coop, 1997).

\section{Material description}

The material used in this study is a calcareous aggregate extracted from a quarry in the northern central region of Portugal. This quarry is explored to obtain selected unbound granular materials (UGMs), being commonly used for bases and sub-bases of transportation infrastructures (Fortunato et al., 2012).

The grain size distribution curve of this sample is presented in Fig. 1, which is classified as a Clayey Gravel (CG) by the unified classification system (USCS - ASTM, 1998), being its particles density 2.73 . The $D_{50}$ effective diameter has the value of $4.1 \mathrm{~mm}$ and the uniformity and curvature coefficients are 875 and 8.25 , respectively, characterising this material as poorly graded. Atterberg limits were determined on the fraction passed on ASTM sieve No. 40 (corresponding to $26 \%$ of the total mass) and values of $22 \%$ for the liquid limit and $31 \%$ for plasticity limit were obtained. This aggregate has a Sand Equivalent Value of 15\% and a Los Angeles Abrasion Index of 30\%, being the water absorption coefficient of $3.9 \%$. The maximum soil dry unit weight obtained by the Modified Proctor test (ASTM, 2004) is $21.4 \mathrm{kN} / \mathrm{m}^{3}$ and the optimum water content is $6.6 \%$. The CBR value in specimens compacted with 12, 25 and 55 blows of the heavy energy for Proctor compaction standard (ASTM, 2004) resulted in the average value of $63 \%$.

Portland cement of high initial strength (CEM I $52.5 \mathrm{R}$, Table 1), was used as bonding agent on these mixtures

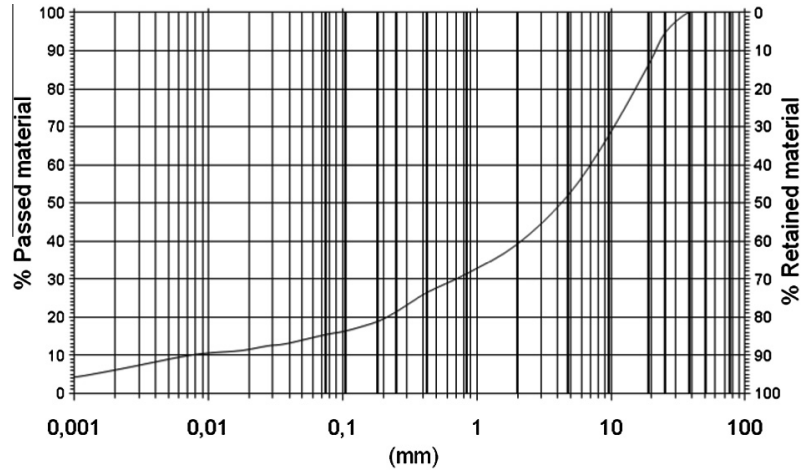

Fig. 1. Grain size distribution curve of the aggregate without cement. 
Table 1

Mechanical characteristics of cement CEM I $52.5 \mathrm{R}$.

\begin{tabular}{lll}
\hline \multicolumn{2}{l}{ Compression strength $(\mathrm{MPa})$} & \\
\hline Initial strength & Final strength & NP EN 196-1 standard \\
2 days & 28 days & (IPQ, 2006) \\
$\geqslant 30$ & $\geqslant 52.5$ & \\
\hline
\end{tabular}

(Secil, 2004). Being a rapid strength cement, it allows a stabilised curing time of 14 days. The unit mass of cement is $\rho_{c}=3100 \mathrm{~kg} / \mathrm{m}^{3}$.

\section{Experimental program}

This study included 15 low energy dynamic tests with ultrasonic transducers, for measuring shear/distortional (S) and compression (P) wave's velocities, 24 triaxial tests, under static/monotonic loading conditions, and 15 indirect tensile tests (commonly designated as Brazilian diametral compression tests). Dynamic and indirect tensile tests were executed in the same specimens. For each value of cement content, $C(1 \%, 2 \%, 3 \%, 4 \%$ and $5 \%$ of the soil dry weight) three specimens were moulded and dynamically compacted, under Proctor's method, for three different compaction degrees $(12,25$ and 55 blows per each of the five adopted layers). They were designated as DC (referring to Diametrical Compression), followed by the cement content and the number of blows used for the compaction of the specimens. Moulding conditions are resumed in Table 2, where cement content, water content $(w)$, unit mass $(\rho)$, initial void ratio $(e)$, initial porosity $(n)$ and volumetric cement content $\left(C_{i v}=V_{c} / V_{t}\right)$ are reported. The ratio of porosity to the volumetric cement content $\left(n / C_{i v}\right)$ proposed by Consoli et al. (2007), has been used for indexation purposes in distinct materials, as explained in Viana da Fonseca et al. (2009a). $V_{c}$ and $V_{t}$ indicate the cement volume and the total volume of the specimen, respectively.

Monotonic triaxial tests were performed on specimens with cement contents between $2 \%$ and $5 \%$ and compacted with 12 or 55 blows. Three equal specimens were moulded to be tested in three different confining pressures $(30,50$ and $100 \mathrm{kPa}$ ). The specimen's designation includes the cement content, followed by the number of blows per layer

Table 2

Moulding conditions of the specimens submitted to dynamic tests and indirect tensile tests.

\begin{tabular}{lllllll}
\hline Specimen & $C(\%)$ & $w(\%)$ & $\rho\left(\mathrm{kg} / \mathrm{m}^{3}\right)$ & $e$ & $n(\%)$ & $V_{c} / V_{t}(\%)$ \\
\hline DC_1\%_12 & 1 & 6.3 & 2075 & 0.40 & 28.57 & 0.63 \\
DC_1\%_25 & 1 & 6.0 & 2199 & 0.32 & 24.13 & 0.67 \\
DC_1\%_55 & 1 & 5.9 & 2311 & 0.25 & 20.19 & 0.70 \\
DC_2\%_12 & 2 & 6.5 & 2073 & 0.41 & 28.88 & 1.26 \\
DC_2\%_25 & 2 & 5.3 & 2169 & 0.33 & 24.76 & 1.33 \\
DC_2\%_55 & 2 & 5.1 & 2317 & 0.24 & 19.48 & 1.42 \\
DC_3\%_12 & 3 & 6.4 & 2073 & 0.41 & 28.93 & 1.89 \\
DC_3\%_25 & 3 & 5.5 & 2226 & 0.30 & 23.02 & 2.04 \\
DC_3\%_55 & 3 & 5.3 & 2346 & 0.23 & 18.70 & 2.16 \\
DC_4\%_12 & 4 & 5.4 & 2083 & 0.39 & 28.01 & 2.55 \\
DC_4\%_25 & 4 & 5.8 & 2197 & 0.32 & 24.36 & 2.68 \\
DC_4\%_55 & 4 & 5.8 & 2305 & 0.26 & 20.63 & 2.81 \\
DC_5\%_12 & 5 & 6.3 & 2104 & 0.39 & 28.01 & 3.19 \\
DC_5\%_25 & 5 & 5.5 & 2194 & 0.32 & 24.36 & 3.35 \\
DC_5\%_55 & 5 & 5.9 & 2331 & 0.25 & 19.94 & 3.55
\end{tabular}

Table 3

Moulding conditions of the specimens submitted to triaxial tests.

\begin{tabular}{lllllll}
\hline Specimen & $C(\%)$ & $w(\%)$ & $\rho\left(\mathrm{kg} / \mathrm{m}^{3}\right)$ & $e$ & $n(\%)$ & $V_{c} / V_{t}(\%)$ \\
\hline 2\%_12_30 & 2 & 6.8 & 1985 & 0.48 & 32.26 & 1.18 \\
2\%_12_50 & 2 & 6.8 & 2019 & 0.45 & 31.02 & 1.20 \\
2\%_12_100 & 2 & 6.8 & 2005 & 0.46 & 31.31 & 1.20 \\
3\%_12_30 & 3 & 6.8 & 2000 & 0.46 & 31.61 & 1.77 \\
3\%_12_50 & 3 & 6.8 & 2008 & 0.46 & 31.33 & 1.78 \\
3\%_12_100 & 3 & 6.8 & 2008 & 0.46 & 31.41 & 1.78 \\
4\%_12_30 & 4 & 6.8 & 2013 & 0.45 & 31.10 & 2.36 \\
4\%_12_50 & 4 & 6.8 & 1991 & 0.48 & 32.39 & 2.32 \\
4\%_12_100 & 4 & 6.8 & 1966 & 0.49 & 33.08 & 2.29 \\
5\%_12_30 & 5 & 7.2 & 1979 & 0.49 & 32.84 & 2.85 \\
5\%_12_50 & 5 & 7.2 & 2001 & 0.47 & 32.20 & 2.88 \\
5\%_12_100 & 5 & 7.2 & 1977 & 0.50 & 33.13 & 2.84 \\
2\%_55_30 & 2 & 6.8 & 2243 & 0.31 & 23.39 & 1.34 \\
2\%_55_50 & 2 & 6.8 & 2263 & 0.29 & 22.76 & 1.35 \\
2\%_55_100 & 2 & 6.8 & 2294 & 0.28 & 21.69 & 1.37 \\
3\%_55_30 & 3 & 6.8 & 2265 & 0.29 & 22.51 & 2.01 \\
3\%_55_50 & 3 & 6.8 & 2244 & 0.31 & 23.43 & 1.99 \\
3\%_55_100 & 3 & 6.8 & 2276 & 0.28 & 21.84 & 2.03 \\
4\%_55_30 & 4 & 6.8 & 2246 & 0.31 & 23.78 & 2.61 \\
4\%_55_50 & 4 & 6.8 & 2218 & 0.32 & 23.98 & 2.61 \\
4\%_55_100 & 4 & 6.8 & 2157 & 0.36 & 26.56 & 2.52 \\
5\%_55_30 & 5 & 7.2 & 2204 & 0.34 & 25.36 & 3.17 \\
5\%_55_50 & 5 & 7.2 & 2209 & 0.33 & 25.01 & 3.19 \\
5\%_55_100 & 5 & 7.2 & 2188 & 0.35 & 25.88 & 3.15 \\
\hline
\end{tabular}

(considering 9 layers) and the confining pressure (see Table 3). Although the individual physical properties (specifically the moulding water and the porosity) of the specimens are not the same as those of the specimens moulded for the dynamic and indirect tensile tests, the range of the volumetric cement content is compatible and therefore, both sets of tests can be used for correlation purposes (Viana da Fonseca et al., 2009a, and Rios et al., 2012).

\section{Equipment}

\section{Dynamic tests}

For the dynamic characterisation of the aggregate-cement specimens two different types of ultrasonic transducers were used, according to the type of the vibration wave propagating through the specimen to be measured.

The used transducers are made of stainless steel housing. Both present a cylindrical shape. They consist on three piezo-crystal conductors of titanium zirconate, with $63.5 \mathrm{~mm}$ of thickness and $8.0 \mathrm{~mm}$ diameter (refer to Amaral et al., 2011, for further details).

The function generator sends a signal directly to the amplifier (manufactured at the University of Waterloo) that increases the signal power up to 800 Volts and provides an adjustable damping. The transmitted and received signals are also linked to the oscilloscope, which allows the acquisition of 2500 points per time window. The system installation, connections and the operating principles are illustrated in Amaral et al. (2013).

\section{Monotonic triaxial tests}

The system, developed by the Institute of Mechanical Engineering and Industrial Management of the University of Porto (INEGI), is formed by a load frame with three 


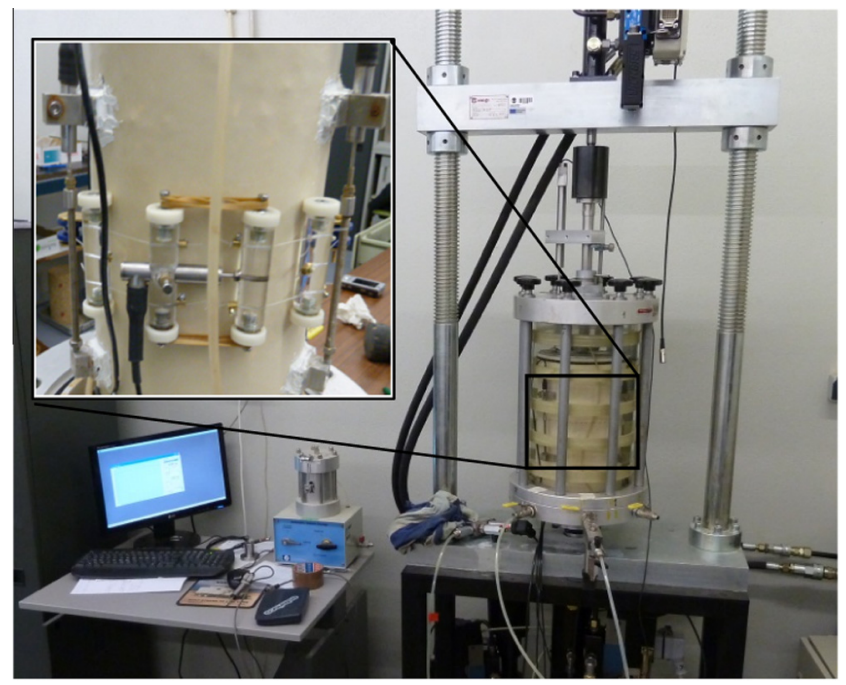

Fig. 2. Equipment for cyclic and monotonic triaxial tests with detail of the local instrumentation for axial and radial strain measurement.

hydraulic actuators controlled by servo-systems, allowing for cyclic loading for axial, radial and back-pressure axes, up to $5 \mathrm{~Hz}$ in frequency, $50 \mathrm{kN}$ in force and $1 \mathrm{MPa}$ in pressures, with a dedicated dynamic set, as well as an independent monotonic hydraulic ram allowing for static tests under displacement and force control (Fig. 2). A large triaxial chamber prepared with inserted local strain measuring devices was specially assembled to allow for high precision stress-strain monitoring (Viana da Fonseca, 1996).

This load was used in the triaxial tests hereby described in quasi-static and monotonic axial loading conditions. The cell can have height adjustment to accommodate different specimens' sizes up to 150 and $300 \mathrm{~mm}$ specimens, diameter and height, respectively.

The system is equipped with an external compression load cell and it is capable of applying a load up to $100 \mathrm{kN}$ with confined pressures up to $1.7 \mathrm{MPa}$. It is equipped with pressure transducers for cell and back pressure measurement, an external linear variable differential transformer (LVDT) with a range of $50 \mathrm{~mm}, 4$ submersible LVDTs for local measurement of the axial and radial displacements during test, with ranges of $10 \mathrm{~mm}$, and a volume gauge with a range of $100 \mathrm{~cm}^{3}$.

Pressure adjustment is performed by the motorized air compressor system of FEUP's geotechnical laboratory. Alternatively, pressure regulation was also performed by two digital pressure/volume controllers by GDS ${ }^{\circledR}$ able to apply pressures up to $2000 \mathrm{kPa}$ and fluid volumes up to $200 \mathrm{~cm}^{3}$. Their automatic pressure control feature is particularly useful during specific stages in triaxial testing, as described below.

\section{Indirect tensile tests}

These tests were performed in a two columns adjustable load frame. It has a capacity of $100 \mathrm{kN}$ and it is equipped with a load cell of the same capacity and $0.006 \mathrm{kN}$ of resolution.
During the tests, radial displacements were measured by four transducers (linear variable differential transformers - LVDTs) complemented by four high precision local deformation transducers (LDTs), manufactured by University of Tokyo (Goto et al., 1991). Although the LVDTs were fixed to external aluminium bars, the LDTs were directly attached to the specimens' surface (Fig. 3).

\section{Testing procedure}

\section{Specimen's preparation}

The samples were prepared according to the type of test they were made for. The specimens for triaxial tests were moulded in cylinders of $150 \mathrm{~mm}$ of diameter and $280 \mathrm{~mm}$ of height. The mixture was done in a humid recipient, where cement was first mixed with the aggregate, joining the water subsequently.

The compaction procedure followed the Proctor compaction protocol described in ASTM (2004). However, since the moulded specimens were bigger than the conventional Proctor moulds, the number of blows was calculated so that the Proctor density was kept constant. Following ASTM (2004), the compaction energy $\left(E_{p}\right)$ is a function of the number of compaction layers, the number of blows per layer, the weight of surcharge, and the falling height of the mass. Using the Proctor compaction energy and the Proctor number of blows (55), a number of 9 layers was determined for the specimen volume.

Keeping this number of layers, the specimens were moulded changing the void ratio (e) and the cement content $(C)$. The desired porosity obtained by changing the number of blows in the compaction of each layer $(N)$, varied between 12,25 and 55 . Each layer was slightly scarified before the compaction of the following to provide a good interlocking. The moulds were placed in the humid chamber during 24 hours with a relative humidity of $96 \%$ and a temperature of $20 \pm 2^{\circ} \mathrm{C}$. After this period the specimens were removed from the mould, their weight and 

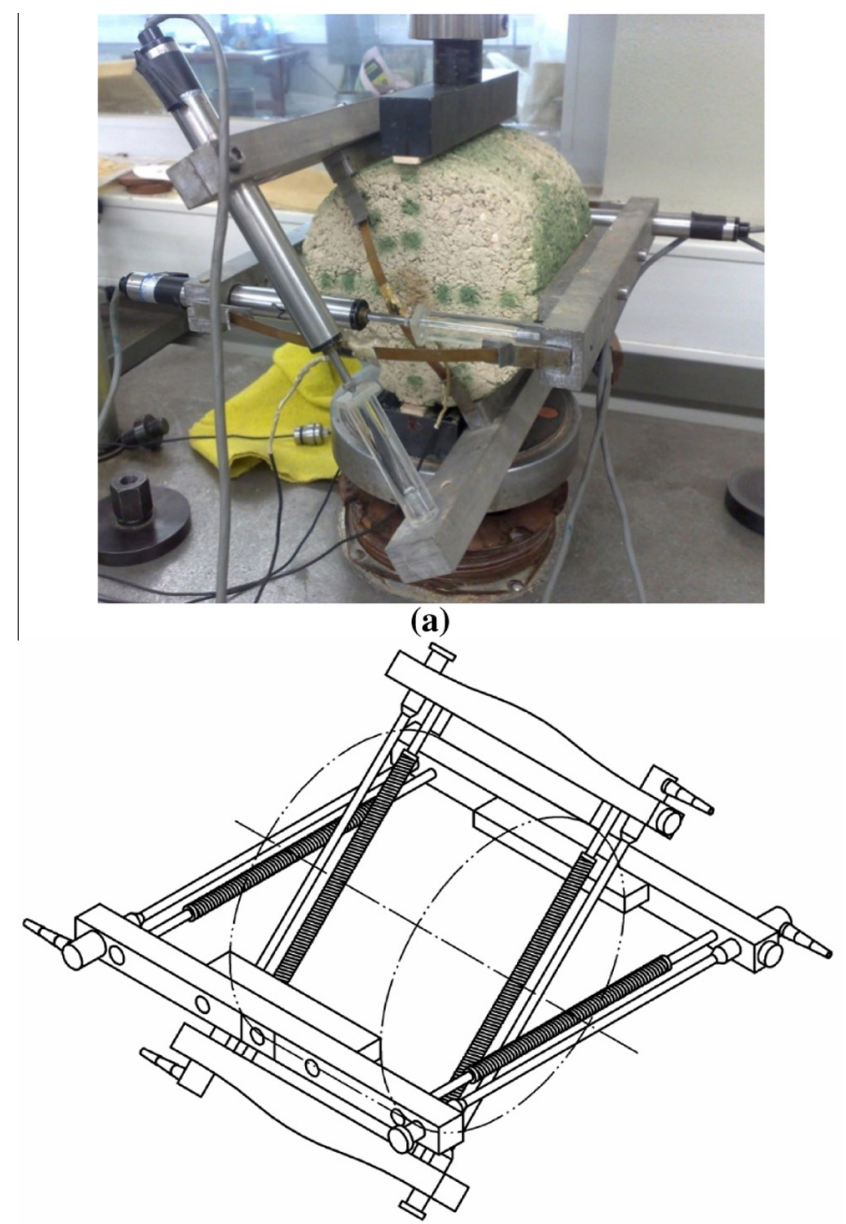

(b)

Fig. 3. (a) Equipment installation for indirect tensile tests; (b) scheme suggested by the European Standard EN 13286-43 (CEN, 2003b).

dimensions were carefully measured, being again placed back in the humid chamber for 13 more days.

The specimens were considered adequate for testing if they matched the following conditions:

- Dry unit weight $\left(\gamma_{d}\right) \pm 1 \%$ of the reference value.

- Water content $(w) \pm 1 \%$ of the reference value.

- Diameter between $150 \pm 1 \mathrm{~mm}$.

- Height between $280 \pm 1 \mathrm{~mm}$.

The specimens for dynamic tests and indirect tensile tests were moulded in similar conditions as described above, using cylinders of $150 \mathrm{~mm}$ of diameter and $145 \mathrm{~mm}$ of height and compacting in 5 layers.

\section{Dynamic tests}

The purpose of the dynamic tests was to study the variation of the elastic Young and shear modulus $\left(E_{0}\right.$ and $G_{0}$, respectively) with the cement content and the compaction degree.
Transducers polarized in a parallel direction of the transducers contact surfaces were used to measure the velocity of the shear waves $\left(V_{S}\right)$. On the other hand, transducers polarized in a perpendicular direction to the contact surfaces were used to measure the longitudinal wave velocity $\left(V_{P}\right)$. This velocity permits to calculate the constrained modulus $\left(M_{0}\right)$ as follows:

$M_{0}=\rho V_{P}^{2}$

On the other hand, $G_{0}$ is given by

$G_{0}=\rho V_{S}^{2}$

Both $V_{S}$ and $V_{P}$ are given by the specimen's height divided by the propagation time of the S-wave and P-wave, respectively. The propagation time was assumed as the time difference between the input signal (impulse) and the first break in the response signal captured by the oscilloscope, in a classical time domain approach using multi-frequency signals to ensure that the wave velocity is independent from the input frequency (Viana da Fonseca et al., 2009b). 
The relationship between $V_{S}$ and $V_{P}$ enables the calculation of the Poisson ratio $v_{0}$ as follows:

$v_{0}=\frac{\left(\frac{V_{P}}{V_{S}}\right)^{2}-2}{2\left(\frac{V_{P}}{V_{S}}\right)^{2}-2}$

Then, the Young's modulus $\left(E_{0}\right)$ can be obtained, using the following equation:

$E_{0}=2\left(1+v_{0}\right) G_{0}$

\section{Monotonic triaxial tests}

Monotonic triaxial tests were performed in order to evaluate strength parameters, such as angle of shearing resistance $\left(\phi^{\prime}\right)$ and cohesion $\left(c^{\prime}\right)$, loading the specimens to failure under different isotropic consolidation pressures $\left(\sigma_{c}^{\prime}\right)$.

After 28 days of curing in a humid chamber, the specimens were instrumented with three axial and one radial LVDT. To allow a better embedment of the anchors which supported the LVDTs, the specimens were drilled before the membrane application. After anchors intrusion, the fixation area was sealed with silicone, to ensure a proper isolation between cell and back pressures, following a procedure adopted by Fortunato (2008).

The acquisition system was connected just after the conclusion of specimens' installation. A valve connected to the cell was opened beginning the flow of the confining liquid into the cell. At the end of this transference the triaxial cell was conveniently sealed. A GDS ${ }^{\circledR}$ hydraulic pump was used to apply the cell pressure (CP), while an air compressor, with lower pressure capacity (up to $700 \mathrm{kPa}$ ), linked to a bladder for isolated interface between air and de-aired water, applied the back pressure at the bottom end (BP) of the specimens. Small pressure increments (around $10 \mathrm{kPa}$ ) were simultaneously applied. Specimen's top valve remained opened to atmospheric pressure. This pressure gradient allowed water percolation of $200 \mathrm{ml}$ removing a significant volume of air from the specimen's voids.

The saturation was automatically programmed to increase $\mathrm{CP}$ and $\mathrm{BP}$ at a rate of $30 \mathrm{kPa} / \mathrm{h}$ starting simultaneously, keeping a very low effective confining pressure $(10 \mathrm{kPa})$. The increase in pressure finished when $\mathrm{CP}$ and $\mathrm{BP}$ reached values of $510 \mathrm{kPa}$ and $500 \mathrm{kPa}$, respectively. This procedure allowed the pore air to dissolve; a manual check of the $\mathrm{B}$ pore pressure parameter gave values not less than 0.93, confirming the saturation of the specimen.

After percolation and saturation, the specimens were submitted to isotropic consolidation $\left(\sigma_{c}^{\prime}=\sigma_{1}^{\prime}=\sigma_{3}^{\prime}\right)$ up to the required pressure (see Table 5 ) with a constant rate of $20 \mathrm{kPa} / \mathrm{h}$. When the volumetric deformation $\left(\varepsilon_{v}\right)$ stabilised, a monotonic deviatoric stress $(q$ - defined by Eq. (5)) was applied by means of a displacement controller at a constant rate of $0.01 \mathrm{~mm} / \mathrm{min}$ in drained conditions.

$q=\sigma_{1}-\sigma_{3}$

The volumetric deformation $\left(\varepsilon_{v}\right)$ was calculated by the axial and radial local deformation transducers being given by:

$\epsilon_{v}=2 \epsilon_{r}+\epsilon_{a}$

For each test the ultimate shear strength $\left(q_{u}\right)$, defined as the maximum deviatoric stress, was computed as well as the evolution of the stiffness modulus $(E)$ with loading level (example in Fig. 4). The Mohr-Coulomb strength parameters $\left(c^{\prime}\right.$ and $\left.\phi^{\prime}\right)$ were then derived for each admixture using the Mohr-Coulomb criterion. During the monotonic shearing the deformability modulus at $50 \%$ of $q_{u}\left(E_{50}\right)$ was also measured.

Another key parameter studied during the analysis of results is the angle of dilatancy, $\psi$. This is defined as the ratio between the increase of volumetric deformation and the increase of distortional deformation:

$\tan \psi=-\frac{\delta \epsilon_{v}}{\delta \epsilon_{S}}$

Where $\varepsilon_{v}$ is defined in Eq. (6) and $\varepsilon_{s}$ is defined as:

$\epsilon_{S}=\epsilon_{a}-\frac{\epsilon_{v}}{3}$

The validity of Eqs. (6) and (8) (that are defined for infinitesimal strain) is guaranteed by the small strain levels attained during the triaxial tests $(<1 \%)$, as it can be seen in the results presented in the following sections.

The value of the angle of shearing resistance is constituted by the contributions of the angle of dilatancy and

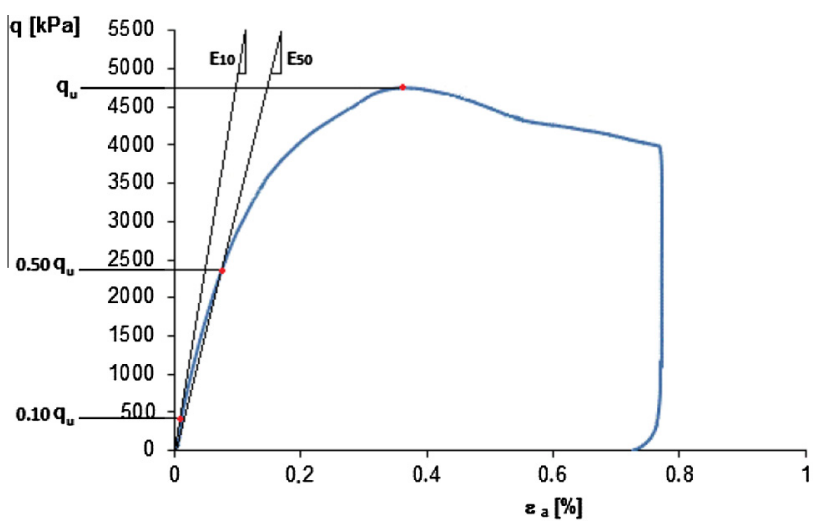

Fig. 4. Example of a $q-\varepsilon_{a}$ graph obtained from a monotonic triaxial test. Values of $q_{u}, E_{10}$ and $E_{50}$ are highlighted. 
the constant volume friction angle or critical state friction angle $\left(\phi_{c v}^{\prime}\right)$, which is a constant of the material. After Bolton (1986) the relation between these parameters in axisymmetric loading conditions is the following:

$\phi_{p\left(c^{\prime}=0\right)}^{\prime}=\phi_{c v}^{\prime}+0.8 \psi$

where $\phi_{p(c /=0)}^{\prime}$ is the peak angle of shearing resistance calculated considering cohesion intercept equal to zero.

\section{Indirect tensile tests}

The indirect tensile tests were performed to obtain the value of indirect tensile strength $\left(q_{t}\right)$ and the indirect tensile elastic modulus $\left(E_{i t}\right)$. In this test a vertical load is applied to the lateral surface of the sample in the diametral direction. According to the European standard CEN (2003a, 2003b), the deformations are monitored continuously with recourse to two sets of extensometers under specific directions; each of them placed between two rigid bars, which are fixed to the specimen. Two pairs of LDTs are fixed on the bases of the specimen and perpendicularly to the loading direction; two other couples of identical transducers are positioned at 60 degrees to the horizontal in order to control the deformations in this direction (see Fig. 3).

According to CEN (2003a), $q_{t}$ is computed by:

$q_{t}=\frac{2}{\pi} \frac{Q}{\phi H}$

where $Q$ is the maximum observed force during diametrical compression and $\Phi$ and $H$ are the specimens diameter and height. This standard also provides an equation to compute $E_{i t}$ :

$E_{i t}=\left(0.273+v+0.726 v^{2}\right) \frac{0.30 Q}{H} \frac{1}{\Delta \phi_{0}}$

where $\Delta \phi_{0}$ and $\Delta \phi_{60}$ are diametrical displacements at $0^{\circ}$ and $60^{\circ}$ when the applied load equals 0.3 times the maximum force, $v$ is the Poisson ratio given by:

$v=\frac{1+0.40 \frac{\Delta \phi_{60}}{\Delta \phi_{0}}}{1.73-1.07 \frac{\Delta \phi_{60}}{\Delta \phi_{0}}}$
Data was processed considering the average values of the four transducers lying on each of the two directions (horizontal and at $60^{\circ}$ to horizontal). Initial values of deformation were corrected to discard the bedding errors of the transducers. In order to minimize the errors associated to the precision, the readings where interpolated by a linear regression.

\section{Results}

\section{Dynamic tests}

The dynamic tests were performed in all specimens presented in Table 2. Since the used cement is a rapid curing agent, no significant differences were observed in the results obtained in the specimens tested at 28 days of curing and after this period (Amaral et al., 2011). $V_{P}$ and $V_{S}$ values are presented in Table 4 as well as the elastic moduli computed from these values $\left(M_{0}, E_{0}, G_{0}\right.$, and $\left.v_{0}\right)$.

The specimens for which the results are not included in Table 4 revealed unacceptable physical values for the dynamic Poisson ratios due to poor signal responses. This phenomenon may be explained by the seismic wave attenuation as a consequence of the high heterogeneity of an aggregate-cement medium.

From the presented results it is clear that the dynamic properties improved with increasing cement content, but also with the specimen density. Both moduli $\left(E_{0}\right.$ and $\left.G_{0}\right)$ are directly related, being their ratio $\left(E_{0} / G_{0}\right)$ almost constant and approximately equal to 2.35 for all the tested specimens. This is due to the very low variations observed in Poisson's ratio values, which is a good indication of the reliability of this methodology.

As referred before, the index defined as the ratio of porosity to the volumetric cement content $\left(C_{i v}\right)$ adjusted by an exponent $(x \in[0,1])$ is designated porosity/cement ratio $\left(n / C_{i v}^{x}\right)$. Some authors [e.g., Consoli et al. (2007), Viana da Fonseca et al. (2009a), Rios et al. (2009, 2012)] have pointed out that $x$ only depends on the type of geomaterial, grain size distribution and mineralogy (Rios et al., 2013) and not on a particular measured property. Fig. 5 shows the results of the performed tests with the adjusted ratio

Table 4

Results of the dynamic tests.

\begin{tabular}{|c|c|c|c|c|c|c|}
\hline Specimen & $V_{P}(\mathrm{~m} / \mathrm{s})$ & $V_{S}(\mathrm{~m} / \mathrm{s})$ & $M_{0}(\mathrm{MPa})$ & $G_{0}(\mathrm{MPa})$ & $v_{0}$ & $E_{0}(\mathrm{MPa})$ \\
\hline DC_1\%_12 & 1543 & 970 & 4940 & 1952 & 0.17 & 4581 \\
\hline DC_1\%_25 & 1624 & 1016 & 5798 & 2267 & 0.18 & 5350 \\
\hline DC_1\%_55 & 1633 & 1027 & 6163 & 2440 & 0.17 & 5718 \\
\hline DC_2\%_12 & 1753 & 1099 & 6371 & 2505 & 0.18 & 5890 \\
\hline DC_2\%_25 & 2164 & 1367 & 10158 & 4053 & 0.17 & 9468 \\
\hline DC_2\%_55 & 2188 & 1379 & 11087 & 4404 & 0.17 & 10315 \\
\hline DC_3\%_12 & 2140 & - & 9493 & - & - & - \\
\hline DC_3\%_25 & 2431 & 1534 & 13151 & 5235 & 0.17 & 12249 \\
\hline DC_3\%_55 & 2770 & - & 18002 & - & - & - \\
\hline DC_4\%_12 & 2429 & 1533 & 12294 & 4895 & 0.17 & 11445 \\
\hline DC_4\%_25 & 2715 & 1717 & 16189 & 6480 & 0.17 & 15114 \\
\hline DC_4\%_55 & 3098 & 1945 & 22118 & 8715 & 0.17 & 20486 \\
\hline DC_5\%_12 & 2720 & 1726 & 15572 & 6271 & 0.16 & 14579 \\
\hline DC_5\%_25 & 3218 & - & 22712 & - & - & - \\
\hline DC_5\%_55 & 3249 & 2071 & 24617 & 10002 & 0.16 & 23151 \\
\hline
\end{tabular}




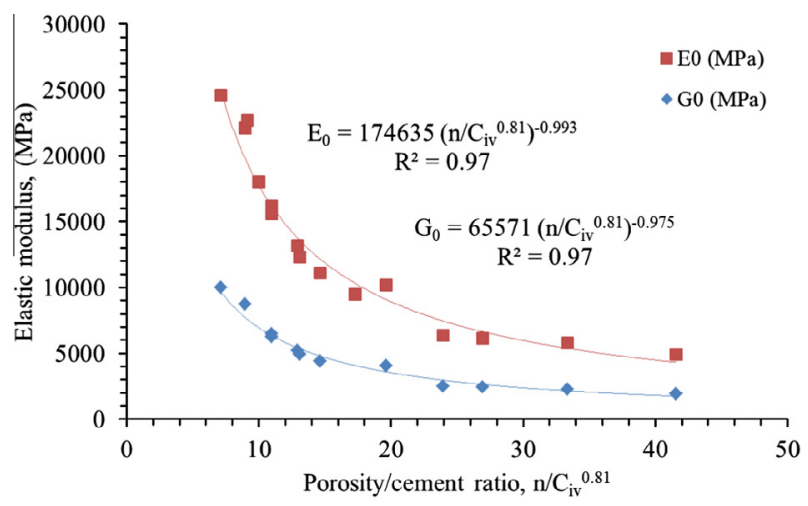

Fig. 5. Relationship between elastic modulus and porosity/cement ratio (dynamic tests).

Table 5

Main properties derived from the monotonic triaxial tests.

\begin{tabular}{|c|c|c|c|c|c|c|c|}
\hline Specimen & $\sigma_{c}^{\prime}(\mathrm{kPa})$ & $q_{u}(\mathrm{kPa})$ & $E_{10}(\mathrm{MPa})$ & $E_{50}(\mathrm{MPa})$ & $E_{50} / E_{10}(\%)$ & $\phi^{\prime}\left({ }^{\circ}\right)$ & $c^{\prime}(\mathrm{kPa})$ \\
\hline 2\%_12_30 & 30 & 1190 & 1666 & 1098 & 66.9 & 39.7 & 255.8 \\
\hline 2\%_12_50 & 50 & 1319 & 1449 & 989 & 68.3 & & \\
\hline 2\%_12_100 & 100 & 1413 & 2631 & 1796 & 68.3 & & \\
\hline 3\%_12_30 & 30 & 2100 & 3125 & 1837 & 58.8 & 41.0 & 414.2 \\
\hline 3\%_12_50 & 50 & 1935 & 4001 & 2671 & 66.8 & & \\
\hline 3\%_12_100 & 100 & 2097 & 7142 & 4215 & 59.0 & & \\
\hline 4\%_12_30 & 30 & 3173 & 1121 & 778 & 69.4 & 41.6 & 468.5 \\
\hline 4\%_12_50 & 50 & 1278 & 1515 & 1078 & 71.2 & & \\
\hline 4\%_12_100 & 100 & 1530 & 1694 & 1139 & 67.2 & & \\
\hline 5\%_12_30 & 30 & 1699 & 2631 & 1639 & 62.3 & 41.8 & 834.7 \\
\hline 5\%_12_50 & 50 & - & 2519 & 1465 & 58.2 & & \\
\hline 5\%_12_100 & 100 & 2425 & 3663 & 2183 & 59.6 & & \\
\hline 2\%_55_30 & 30 & 2241 & 3225 & 2117 & 65.6 & 58.0 & 352.1 \\
\hline 2\%_55_50 & 50 & 3094 & 3333 & 2360 & 70.8 & & \\
\hline 2\%_55_100 & 100 & 3857 & 3571 & 2502 & 70.1 & & \\
\hline 3\%_55_30 & 30 & 4751 & 5263 & 3323 & 63.1 & 58.1 & 639.9 \\
\hline 3\%_55_50 & 50 & 5320 & 4545 & 3302 & 72.7 & & \\
\hline 3\%_55_100 & 100 & - & 11124 & 7858 & 70.6 & & \\
\hline 4\%_55_30 & 30 & 4818 & - & - & - & - & - \\
\hline
\end{tabular}

for both $E_{0}$ and $G_{0}$, which in fact have essentially the same shape, as a consequence of the relative constancy of the dynamic Poisson's ratio.

The index $\left(n / C_{i v}^{x}\right)$ proved to correlate very well with the dynamic properties of the aggregate-cement. Test results showed a very good coefficient of determination $\left(R^{2}\right)$, equal to 0.97 , for both $E_{0}$ and $G_{0}$. Moreover, the empirical exponent $x$, which was determined by maximizing the values of $R^{2}$ in the power trendlines, remained the same, giving a value of 0.81 , which is in agreement with the above referred publications. The value of exponent $x$ was determined for each graph by varying its value in the interval $[0,1]$ and with increments of 0.1 . For each value of $x$, the corresponding graph relating the particular variable with the adjusted ratio was plotted and the power trendline was calculated with its relative $R^{2}$ parameter; so, for each value of $x$, a value of $R^{2}$ corresponded. Thus, the value of $x$ was determined for each specific variable as the value that maximized the parameter $R^{2}$ of the power trendline.

\section{Monotonic triaxial tests}

The geotechnical parameters obtained from the monotonic triaxial tests are summarized in Table 5. An example of stress curves obtained in the specimens 2\%_12 and 2\%_55 is plotted in Fig. 6.

The Mohr-Coulomb failure criterion was used to compute the angle of shearing resistance $\left(\phi^{\prime}\right)$ and the cohesion intercept $\left(c^{\prime}\right)$ for admixtures compacted with the same number of blows and similar cement contents. The initial tangent deformability modulus $\left(E_{10}\right)$ was assumed as the secant modulus at $10 \%$ of peak deviatoric stress in a $q$ vs. $\varepsilon_{a}$ plane. Thus, it is expected that $E_{10}$ has higher values than the secant modulus for $50 \%$ of failure $\left(50 \%\right.$ of $q_{u}$ ), here designated as $E_{50}$.

The results illustrated in Table 5 indicate that, although the deviatoric strength increases with the number of compaction blows, this tendency has a large dispersion in $q_{u}$. Several specimens in the same admixtures presented a smaller value of $q_{u}$ when consolidated to higher pressures. 


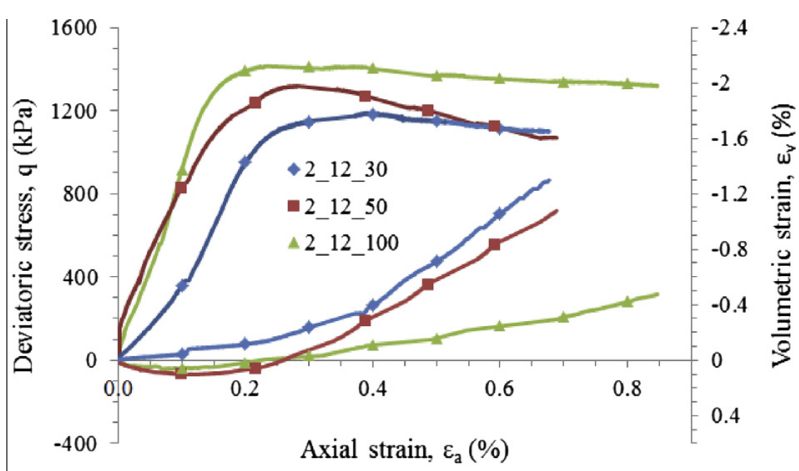

(a)

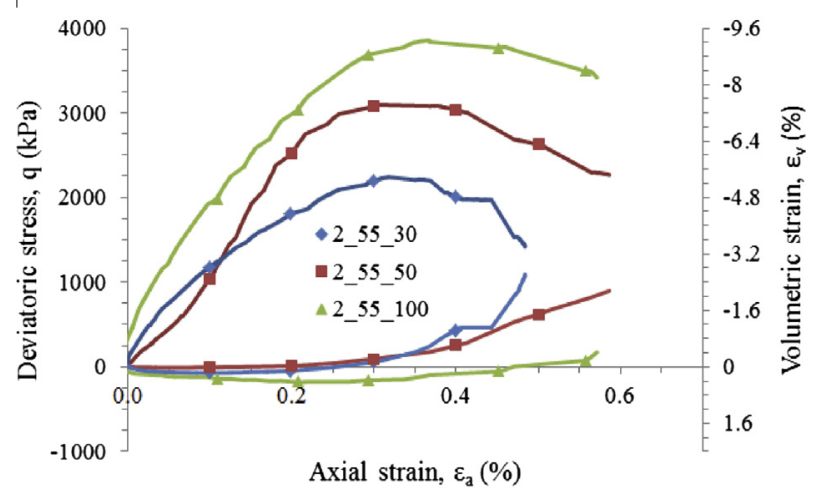

(b)

Fig. 6. Results of triaxial tests for specimens (a) 2\%_12 and (b) 2\%_55.

These results may be related to non-uniformity (heterogeneity between the coarse-grained specimens), but shall also be associated to induced structural damage (cementitious bonding tends to break) during consolidation under higher pressures. These fluctuations lead to difficulties in computing the effective shear strength parameters, in addition to strain localization associated to fragile failure, of such cemented and dense state conditions, which had to be dealt with extra judgment.

On the other hand, the increase in stiffness is in perfect agreement with the increase in compaction energy (the number of blows per layer and cement content). The evolution of the stiffness modulus with the loading level can be represented by the ratio $E_{50} / E_{10}$ indicating the degradation index of this cement-aggregate under diverse state conditions. From the values included in Table 5, there was no clear pattern of marked variation for this index with the density and cementation, allowing for an estimation of an average value of $66.0 \%$, being the specimen 5\%_12_50 the most discrepant one with an absolute deviation of $7.8 \%$. This is to be developed in future works.

Due to the heterogeneity of this material, less usual procedures were necessary for the analysis of the results. The values of the angle of shearing resistance directly obtained from the analysis of the Mohr-Coulomb failure criterion varied significantly. Therefore, a more specific approach was used based on the scheme of Fig. 7, considering that the cohesive intercept increases with cement content while the constant volume friction angle is independent of the cement content. Thus, the peak strength envelopes in the $p^{\prime}-q$ plane were adjusted with a selective cohesive intercept $\left(c^{\prime}\right)$ and an angle of shearing resistance $\left(\phi^{\prime}\right)$ incorporating the friction component and the dilatancy, in the terms described in what follows.

Once the strength peak values were defined, the two granular components were assessed: the component parcel due to friction angle in ultimate and critical conditions $\left(\phi_{c v}^{\prime}\right)$ and the dilatancy. The former angle $\left(\phi_{c v}^{\prime}\right)$, being in ultimate conditions, was defined when the cement bonds are completely destructured and the dilative parcel is nil. The results of the set of triaxial tests with lower cement content and compaction level (2\%_12) in ultimate conditions were considered: for the definition of $\phi_{c v}^{\prime}$, this set of tests is the most likely to rapidly reach critical conditions and the experimental evidences confirm this tendency (see Fig. 6a). The value of the constant volume friction angle determined for this set of tests $\left(37^{\circ}\right)$ was assumed equal for all the mixtures. Then, from the peak strength envelopes and assuming no cohesion intercept, the value of $\phi_{p\left(c^{\prime}=0\right)}^{\prime}$ was calculated, while, using Eq. (9), the values of the angle of dilatancy $(\psi)$ were deduced. These values of the angle of dilatancy at peak shear stress are lower than those inferred directly from the tests results, that is from the ratio between the volumetric and axial strain, using Eq. (7) (see the comparison in Table 6). Moreover, from those values it is evident that the maximum value of the angle of dilatancy 


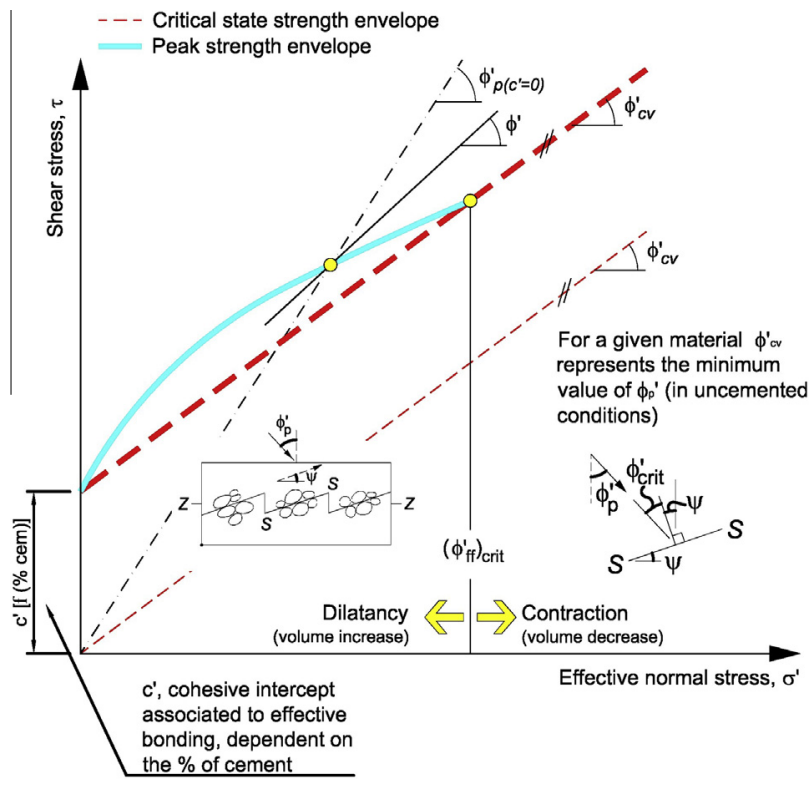

Fig. 7. Decomposition of the strength parameters in granular peak strength (frictional critical component and dilative component) and effective cohesive intercept due to cementation (extended based on Bolton, 1986).

Table 6

Values of the angles of dilatancy calculated with Bolton (1986) relation and from the direct interpretation of data results.

\begin{tabular}{lllll}
\hline Set of tests & $\phi_{p\left(c^{\prime}=0\right)}^{\prime}\left({ }^{\circ}\right)$ & ${\phi^{\prime}}_{c v}\left({ }^{\circ}\right)$ & $\psi_{\text {Bolton }}\left(^{\circ}\right)$ & $\psi_{\text {direct }}\left(^{\circ}\right)$ \\
\hline 2\%_12 & 63.9 & 37 & 33.6 & 46.7 \\
3\%_12 & 68.6 & 37 & 39.5 & 54.3 \\
$4 \% \_12$ & 68.7 & 37 & 39.6 & 48.3 \\
5\%_12 & 72.9 & 37 & 44.9 & 52.6 \\
2\%_55 & 68.0 & 37 & 38.8 & 56.1 \\
3\%_55 & 71.7 & 37 & 43.4 & 56.2 \\
\hline
\end{tabular}

does not correspond to the peak deviator stress as it clearly develops always after the peak while the soil is softening, a pattern common to all naturally and artificially cemented materials (Viana da Fonseca, 2003). This means that the value of $\psi$ calculated with Bolton (1986) relation only accounts for the frictional part of shear strength, while the angle of dilatancy directly calculated at peak is still affected by a component of bonding given by the cement, which might be related with clusters of soil and cement and not with the individual grains.

Relying on the concept of the porosity/cement ratio $\left(n / C_{i v}^{x}\right)$ presented above, which expresses the dual component of density and cementation degree, the variation of the cohesive and dilatancy components of the shear strength was studied. Figs. 8 and 9 present the obtained results.

From the plotted values and the power regressions shown in the figures, a good correlation is obtained for the values of the angle of dilatancy $(\psi)$ with $n / C_{i v}^{x}$, with a coefficient of determination equal to 0.90 . For the effective cohesion intercept the relationship is not as good as for dilatancy, with the coefficient $R^{2}$ equal to 0.81 , but it is still considered very promising taking into account the significant variability of these coarse granular materials. The

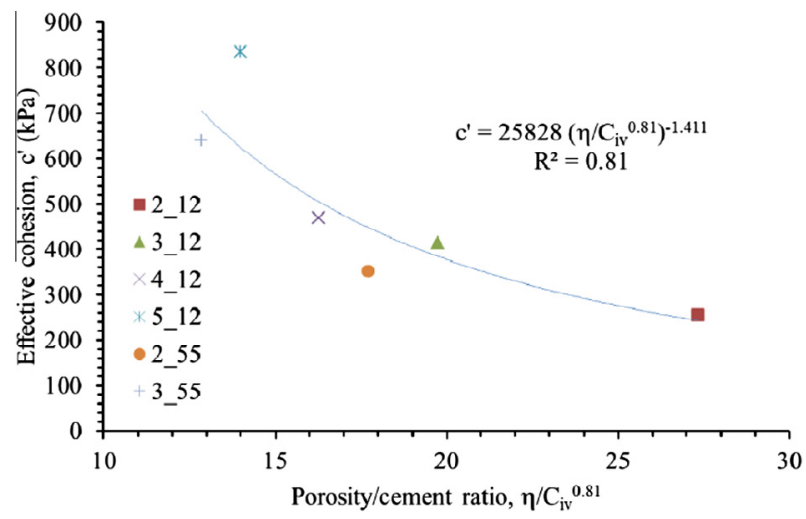

Fig. 8. Relationship between effective cohesion and porosity/cement ratio (triaxial tests). 


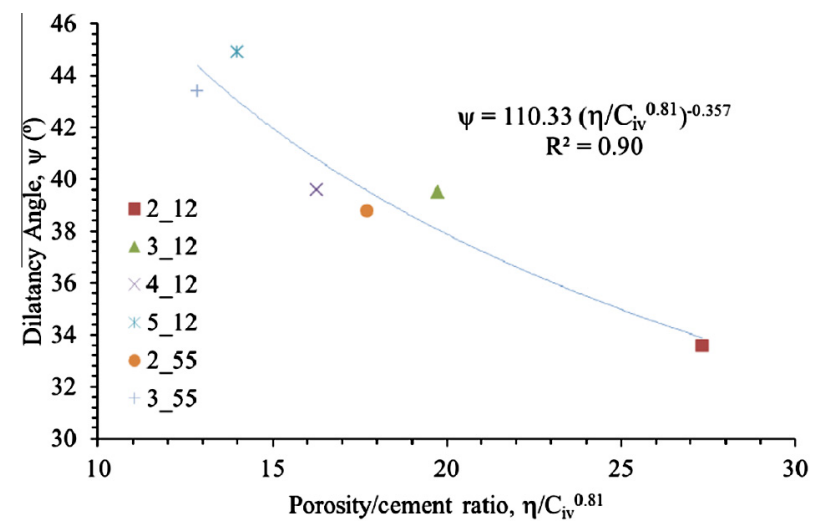

Fig. 9. Relationship between angle of dilatancy and porosity/cement ratio (triaxial tests).

Table 7

Results of the indirect tensile tests.

\begin{tabular}{lcrrrl}
\hline Specimen & $Q(\mathrm{kN})$ & $q_{t}(\mathrm{kPa})$ & $E_{i t}(\mathrm{MPa})$ & $q_{t} / E_{i t}(\%)$ & $v$ \\
\hline DC_1\%_12 & 3.01 & 88 & 438 & 20 & 0.42 \\
DC_1\%_25 & 5.94 & 175 & 1047 & 17 & 0.40 \\
DC_1\%_55 & 8.10 & 236 & - & - & - \\
DC_2\%_12 & 6.81 & 199 & 534 & 37 & 0.32 \\
DC_2\%_25 & 9.86 & 286 & - & - & - \\
DC_2\%_55 & 13.98 & 409 & 4831 & 8 & 0.13 \\
DC_3\%_12 & 10.43 & 306 & 2043 & 15 & 0.16 \\
DC_3\%_25 & 12.96 & 382 & 7393 & 5 & 0.35 \\
DC_3\%_55 & 26.43 & 785 & 15240 & 5 & 0.25 \\
DC_4\%_12 & 14.43 & 421 & 3852 & 11 & 0.36 \\
DC_4\%_55 & 28.82 & 834 & 8509 & 10 & 0.18 \\
DC_5\%_12 & 21.28 & 619 & - & - & - \\
DC_5\%_25 & 35.60 & 1031 & 10118 & 10 & 0.20 \\
DC_5\%_55 & - & - & - & - & - \\
\hline
\end{tabular}

porosity/cement ratio expressed for each mixture is the average of the ratios of the three specimens. This ratio appears to be a good indexing parameter, since it can reproduce the behaviour of specimens with different compaction and cement content under a single variable. Figs. 8 and 9 show that specimens with different cement content and/or compaction degree but similar ratio have similar values of cohesion and dilatancy angle.

\section{Indirect tensile tests}

After the dynamic characterisation of the aggregatecement, the specimens were tested in diametral compression (Brazilian tests) for indirect evaluation of the tensile strength and stiffness. The European Standards EN1328642 (CEN, 2003a) and EN13286-43 (CEN, 2003b) were followed for these splitting tensile tests. Table 7 summarizes the results of the tests. The computed properties were the indirect tensile strength $\left(q_{t}\right)$, the tensile modulus $\left(E_{i t}\right)$ and the Poisson's ratio $(v)$.

In accordance to the terms of the procedure described in the referred European standards, the calculation of these values followed the Eqs. (10)-(12).

The specimens that did not present reasonable values for the Poisson ratio were not included in Table 7. Moreover, it was not possible to obtain results from the specimen DC_5\%_55 due to an acquisition problem during the test. The relationship between $E_{i t}$ and $q_{t}$ showed smaller scatter in the specimens compacted with higher density. Thus, this can be an indication that, for these specimens, compaction degree has a more important role in the strength gain than in stiffness increase.

Table 7 shows, once more, a significant stiffness improvement with the cement content and number of blows. The average $v$ value of 0.28 is higher than the value

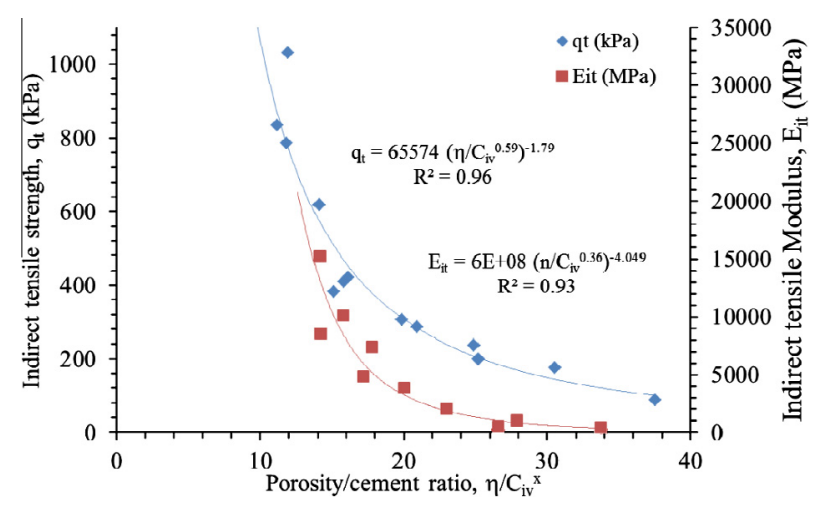

Fig. 10. Relationship between indirect tensile strength and porosity/cement ratio (indirect tensile tests). 


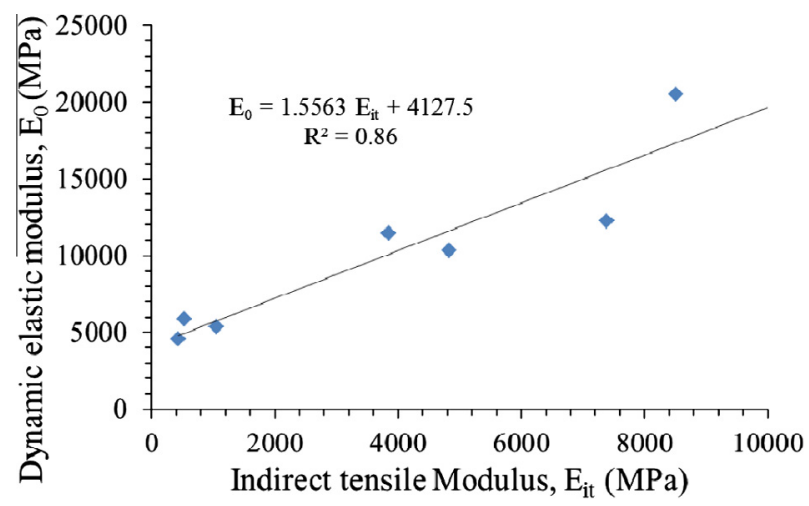

Fig. 11. Relationship between dynamic elastic modulus and indirect tensile modulus.

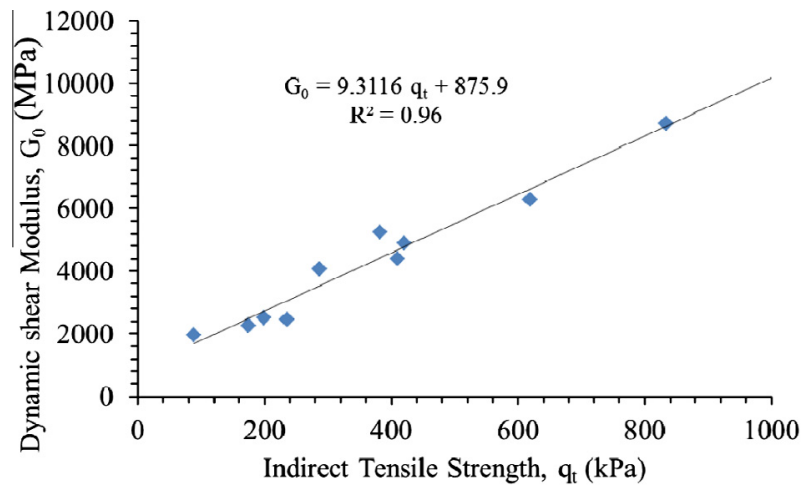

Fig. 12. Relationship between dynamic shear modulus and indirect tensile strength.

$\left(v_{0}=0.17\right)$ deduced from the seismic wave analysis due to the different strain level involved in both tests. Despite those values, $v$ presented more scatter than $v_{0}$, meaning that the seismic waves' measurements are more reliable for the purpose of Poisson ratio estimation. Conversely to the monotonic triaxial treatment, the indirect tensile tests were conducted with no confinement pressure (CP). Therefore, the $n / C_{i v}^{x}$ normalization may be applied without any influence of confining pressure. Fig. 10 shows the results of such indexation.

The best regression to this indexation demonstrated that the optimal exponent $\left(x=0.59\right.$ for $q_{t}$ and $x=0.36$ for $E_{i t}$ ) for the adjustment of the volumetric cement content in the porosity/cement ratio depends not only on the type of soil but also on the measured property, which is in disagreement with previous analyses in finer materials reported in Consoli et al. (2007), Viana da Fonseca et al. (2009a) and Rios et al. (2009), demanding for new and more extensive studies in coarse material, in future researches. Nevertheless, this variation with $n / C_{i v}^{x}$ proved to give a good framework for the evaluation of these properties from the state conditions of each specimen. Fig. 10 showed a good correlation with the indirect tensile strength and tensile modulus in agreement with Fig. 5 results.

\section{Discussion}

The results presented in the precedent sections proved that the mechanical properties of an aggregate-cement are correlated between them. In this section, relations between results of different tests will be compared. Triaxial compression tests and indirect tensile tests with very precise deformation monitoring were not easy to perform. On the contrary, seismic wave tests are an easiest and economic technique to evaluate low strain stiffness properties. The definition of the correlations that can give a direct correspondence between dynamic stiffness parameters at very low strains and the properties deduced in triaxial tests or in indirect tensile tests such as low to medium strain stiffness parameters and strength parameters would be an obvious advantage. In this sense, Fig. 11 shows the comparison between the dynamic (elastic) Young's modulus $\left(E_{0}\right)$ derived from seismic waves' measurements and that derived from indirect tensile test $\left(E_{i t}\right)$.

It is evident a good correlation between the two moduli (with a $R^{2}$ parameter greater than 0.8 ), especially for low values of indirect tensile modulus. For increasing values, data is more dispersed because of the increased difficulty in obtaining a reliable measurement of $E_{i t}$ in very rigid specimens; thus, the founded relationship with a more 


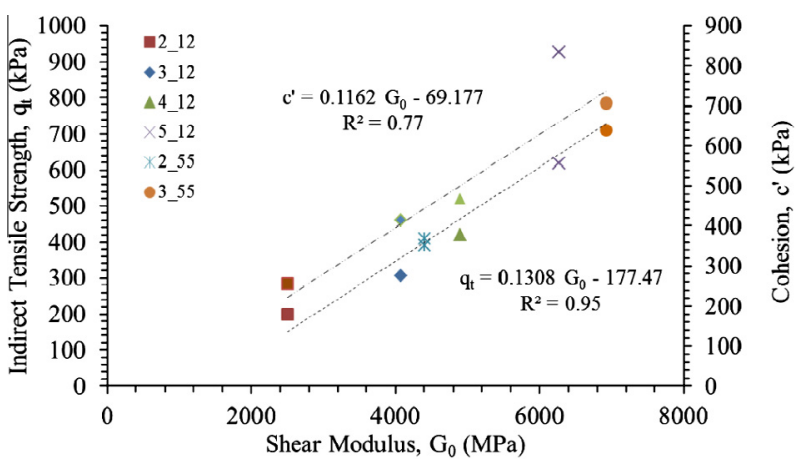

Fig. 13. Relationship between indirect tensile strength and dynamic shear modulus with the effective cohesive intercept.

stable property as $E_{0}$ gives the possibility to characterize the aggregate with more reliability and less effort.

The relation between the dynamic shear modulus and the indirect tensile strength is shown in Fig. 12. In this case, the correlation has a much higher $R^{2}$, due to the easier assessment of the indirect tensile strength during the tests. The very good correlation with the shear modulus obtained from dynamic tests confirms that, for this aggregate, it is possible to link results from different tests and shows that the strength and stiffness parameters are strongly related. Fundamentally, the authors believe that the indirect tensile strength and dynamic shear modulus are strongly associated to interparticular bonded structure, a direct function of the cement content, mobilized in low to very low strain levels (Consoli et al., 2011).

Fig. 13 shows a tentative proposal for a simple but useful approach to derive values of the indirect tensile strength $\left(q_{t}\right)$ and the effective cohesive intercept $\left(c^{\prime}\right)$ from the values of the dynamic shear modulus $\left(G_{0}\right)$ in a double graph relationship. The obvious advantage of this chart is the fact that $G_{0}$, calculated from shear wave's velocities, is cheap, fast and non-destructive, which will ease the estimation of such important design properties, as $q_{t}$ and $c^{\prime}$, in subgrades for transportation infrastructures.

The lines in Fig. 13 indicate that all the properties $\left(G_{0}, c^{\prime}\right.$, and $q_{t}$ ) increase consistently with cement content and compaction degree. Although $R^{2}$ does not show as good values as in the single property analysis, mostly because of the limited number of tests, a coefficient of determination close to 0.8 is sufficiently significant to give confidence to this correlation between those properties. However, the application of these laws should be done if higher safety factors were adopted, while more extensive data can be accumulated.

\section{Conclusions}

From the data presented in this paper the following main conclusions can be drawn:

- All geomechanical properties, both stiffness (dynamic for very small strain levels - and static - small to medium strain levels) and strength (in compression and in tension), showed a positive evolution with the increasing cement content, as well as with the compaction degree, although in different degrees.
- The ultimate strength measured for aggregate-cement, isotropically consolidated with confinement pressures up to $100 \mathrm{kPa}$, revealed a significant heterogeneity due to some diversity of the specimens, but also for the different consequences of these pressures in inducing damages to the structure prior to shear testing. A thorough analysis of the values allowed the definition of the most representative frictional and cohesive components.

- The angle of friction at critical state is not cement dependent although the angle of shearing resistance, which incorporates the frictional component and the dilatancy, is strongly influenced by the initial void ratio imposed in the specimen's compaction. Bearing this in mind, a distinction between the purely friction parcel (the critical angle of friction) and the dilative component (angle of dilatancy) was made to look for a competent theoretical base for the indexation of each of these factors.

- Effective cohesion intercept, indirect tensile strength and dynamic shear modulus are properties which correlate strongly and may be easily deducted from each other.

- The porosity/cement ratio, $n / C_{i v}^{x}$ (Consoli et al., 2007; Viana da Fonseca et al., 2009a; Rios et al., 2009, 2012) proved to be a good index for deriving geomechanical parameters for design purposes, as far as the exponent that affects the cement content is adapted to each of those properties. The results presented in this paper indicate that this index, not only varies with the type of soil, but also seems to vary with the measured properties, specially, in two main groups: those obtained in waves' dynamic tests $\left(E_{0}\right.$ and $\left.G_{0}\right)$ and in well controlled triaxial tests $\left(c, \phi^{\prime}\right.$, and, $\left.\psi\right)$, by one side, and others, obtained in indirect tensile tests $\left(q_{t}\right.$ and $\left.E_{i t}\right)$, which can have some specific features, still not controlled.

\section{Acknowledgements}

This research was developed in FCT research unit CEC (in FEUP) and on the projects SIPAV (Pre-Cast Innovative Solutions for High-Speed Railway Lines - SI IDT - 3440/ 2008) and PTDC/ECM/099475/2008, financed by the European Community (QREN/UE/FEDER), Operational Program for Competitive Factors "COMPETE". 
The authors acknowledge Prof. Eduardo Fortunato, from LNEC, for the valuable suggestions on implementing local displacement instrumentation on the triaxial tests specimens.

\section{References}

Âhnberg H. On yield stresses and the influence of curing stresses on stress path and strength measured in triaxial testing of stabilized soils. Can Geotech J 2007;44:54-66.

Amaral MF, Viana da Fonseca A, Oliveira Braga T. Soils and aggregates for high-speed railways. Proc 5th Portuguese-Brazilian Conf, Gramado, Brasil 2010;1:157-168.

Amaral MF, Viana da Fonseca A, Arroyo M, Cascante G, Carvalho J. Compression and shear wave propagation in cemented-sand specimens. Géotech Lett 2011;1:79-84. http://dx.doi.org/10.1680/ geolett.11.00032.

Amaral MF, Viana da Fonseca A, Rios S. Numerical methodology to minimize resolution and sensitivity effects in P-wave measurements. Geotech Test J ASTM 2013;36(2):178-86.

Bolton MD. The strength and dilatancy of sands. Géotechnique $1986 ; 36(1): 65-78$

ASTM. D2487. Standard practice for classification of soils for engineering purposes (unified soil classification system). USA: American Society for Testing Materials; 1998.

ASTM. D1557. Standard test methods for laboratory compaction characteristics of soil using modified effort. USA: American Society for Testing Materials; 2004.

CEN. EN 13286-42: unbound and hydraulically bound mixtures - Part 42 test method for the determination of the indirect tensile strength of hydraulically bound mixtures. Brussels: European Comity of Normalization; 2003a.

CEN. EN 13286-43: unbound and hydraulically bound mixtures - Part 43: test method for the determination of the modulus of elasticity of hydraulically bound mixtures. Brussels: European Comity of Normalization; 2003b.

Consoli NC, Foppa D, Festugato L, Heineck K. Key parameters for strength control of artificially cemented soils. J Geotech Geoenviron Eng 2007;133(2):197-205.

Consoli NC, Viana da Fonseca A, Caberlon Cruz R, Rios Silva S. Voids cement ratio controlling tensile strength of cement treated soils. J Geotech Geoenviron Eng Tech Note 2011;137(11):1126-31.

Cuccovillo T, Coop MR. The measurement of local axial strains in triaxial tests using LVDTs. Tech Note Géotech 1997;1(47):167-71.

Fortunato E, 2005. Renewal of railway platforms. Studies about bearing capacity. Ph.D. Thesis, Faculty of Engineering, University of Porto, Portugal (in Portuguese).

Fortunato E, 2008. Soil improvement: an alternative solution with high potential. Seminar on 'Materials Improvement with Lime and Cement for Transportation Infrastructures'. ISBN: 978-972-752-103-6 (http:// paginas.fe.up.pt/ tratcica/). Porto, Portugal (in Portuguese).

Fortunato E, Paixão A, Fontul S. Improving the use of unbound granular materials in railway sub-ballast layer. In: Miura et al., editors. Advances in transportation geotechnics II. London: Taylor \& Francis Group; 2012.

Gasparre A, Coop MR. Quantification of the effects of structure on the compression of a stiff clay. Can Geotech J 2008;45:1324-34.

Ghosh H, Subbarao C. Tensile strength bearing ratio and slake durability of class F fly ash stabilized with lime and gypsum. J Mater Civ Eng 2006;18(1):18-27.

Goto S, Tatsuoka F, Shibuya S, Kim Y-S, Sato T. A simple gauge for local small strain measurements in the laboratory. Soils Found 1991;31(1):169-80.
Heisey JS, Stokoe KH, Meyer AH. Moduli of pavement systems from spectral analysis of surface waves. In: Transportation research record 852. Washington, D.C., USA: Transportation Research Board, National Research Council; 1982. p. 22-31.

IPQ, 2006. NP EN 196-1: methods of testing cement - Part 1 Determination of mechanical strengths. Portuguese Institute for Quality, Caparica, Portugal (In Portuguese).

Khan Z, Cascante G, El-Naggar H. Dynamic properties of cemented sands using ultrasonic waves. Can Geotech J 2011;48(1):1-15.

Leroueil S, Vaughan A. The general and congruent effects of structure in natural soils and weak rocks. Géotechnique 1990;40(3):438-67.

Lohani TN, Tatsuoka F. Strengthening of the weakly-cemented gravels with curing period. TC29 - Proc Roma Geotechnical Symposium, March 2006, "La Sapienza", Italia.

Mitchell JK. Fundamentals of soil behaviour. New York, USA: John Wiley \& Sons; 1976.

Rios S, Viana da Fonseca A, Consoli NC. Strength and stiffness properties of mixtures of granitic soil-cement. Proceedings of the 17th International Conference of Soil Mechanics and Foundation Engineering, Alexandria, Egypt, 2009;1:312-315.

Rios S, Viana da Fonseca A, Baudet B. The effect of the porosity/cement ratio on the compression behavior of cemented soil. J Geotech Geoenviron Eng 2012;138(11):1422-6. http://dx.doi.org/10.1061/ (ASCE)GT.1943-5606.0000698.

Rios S, Viana da Fonseca A, Consoli NC, Floss M, Cristelo N. Influence of grain size and mineralogy on the porosity/cement ratio. Géotech Lett 2013;3:130-6. issue July-September, August 2013.

Secil, 2004. Available at: <http://www.secil.pt/pdf/CEMI525R.pdf> (accessed: 30 January 2014)

Selig ET, Li D. Resilient modulus for fine-grained sub-grade soils. J Geotech Eng 1994;120(6):939-57.

Symes M, Burland JB. Determination of local displacements on soil samples. Geotech Test J ASTM 1984;7(2):49-59.

Tatsuoka F, Kim YS, 1984. Deformation of shear zone in sedimentary soft rock observed in triaxial compression. Proc Localization and Bifurcation Theory for Soils and Rocks. Balkema, Rotterdam. p. 181187.

Tatsuoka F, Ishihara M, Di Benedetto H, Kuwano R. Time-dependent compression deformation characteristics of geomaterials and their simulation. Soils Found 2002;42(2):103-38.

Topa Gomes A, 2009. Elliptical shafts by the sequential excavation method. The example of Metro do Porto. D.Sc. Thesis, University of Porto, Faculty of Engineering. p. 332 (in Portuguese).

Vaughan PR, Kwan CW. Weathering, structure and in situ stress in residual soils. Géotechnique 1984;34(1):43-59. London.

Viana da Fonseca A, 1996. Geomechanics in residual soils from Porto Granite. Criteria for the Design of Shallow Foundations. Ph.D. Thesis, Faculty of Engineering, University of Porto, Portugal (in Portuguese).

Viana da Fonseca A, 2003. Characterizing and deriving engineering properties of a saprolitic soil from granite, in Porto. In: Leroueil S, Phoon KK, Tan TS, Hight DW, editors. Characterization and engineering properties of natural soils 2, Vol. 2, p. 1341-1378.

Viana da Fonseca A, Coutinho RQ, 2008. Characterization of residual soils. The 3rd International Conference on Site Characterization, p. 195248.

Viana da Fonseca A, Caberlon Cruz R, Consoli NC. Strength properties of sandy soil-cement admixtures. Geotech Geol Eng 2009a;27(6):681-6.

Viana da Fonseca A, Ferreira C, Fahey M. A framework interpreting bender element tests, combining time-domain and frequency-domain methods. Geotech Test J 2009b;32(2):1-17.

Viana da Fonseca A, Rios S, Amaral MF, Panico F. Fatigue cyclic tests on artificially cemented soil. Geotech Test J 2013;36(2):1-9.

Werkmeister S, 2003. Permanent deformation behaviour of unbound granular materials in pavement constructions. Ph.D. Thesis, Technischen Universität Dresden. 